\title{
Technological Imperatives, Productivity and Insurance Costs*
}

\author{
by William J. Baumol**
}

\section{The issue}

In the 1989 election for Governor of the State of New Jersey there was no issue to which the two leading candidates devoted more attention than to the rates inhabitants of the State were paying for their automotive insurance. Though neither was willing to indicate how he proposed to perform that act of magic, they both were prepared to compete in their vows to bring down the rates, presumably without reduction of service. This is a scenario that has been replicated in many political jurisdictions, and it is a continuing burden carried by the insurance industry and by a few other economic activities.

While such debates are characterized to a considerable extent by resort to fantasy rather than recourse to logic, there is in fact a good reason why this industry is among the small number persistently singled out for such unwelcome attention. The insurance industry is plagued by persistently rising costs which force its rates to rise cumulatively to a degree that inevitably make that industry a perpetual target of suspicion (see Figure 2, below). As when any such problem arises the politicians and the more-gullible members of the public find it irresistible to attribute the phenomenon to villainous behavior - to mismanagement, greed and even worse. However, as will be shown in this paper, much and perhaps even most of the problem can be traced to a source which entails no misdeeds but is, rather, the result of impersonal technological imperatives - the nature of the technology necessary to produce the services that are the outputs of the insurance industry. ${ }^{1}$

I will also discuss why technological breakthroughs, notably the evolution of the computer, appear to have had little effect on the industry's productivity growth even though it has probably affected profoundly the way in which the business is conducted.

The logic of the analysis together with some empirical evidence will go far to explain why the rates charged for various types of insurance are so often a prime political issue, and will indicate that much of the contention has its roots in misunderstanding of the economic relationships that provision of insurance services entail.

* This paper has been presented for the 14th Annual Lecture of the Geneva Association in Brussels, June 12, 1990.

** Director, C. V. Starr Center for Applied Economics, New York University, and Professor of Economics, Princeton University. The author is deeply grateful to the C. V. Starr Center for its generous support of the research underlying this paper. He is also thankful to Professors Denis Kessler and Pestieau for their helpful comments on an earlier draft of this paper.

1 Because of the nature of the available data the discussion will focus largely on automotive insurance; however, most of the basic analysis clearly applies to other for'ms of insurance as well. 


\section{Some facts on the industry's productivity performance}

Unlike products whose prices are determined on a competitive market, the history of insurance rates cannot be used as a legitimate indicator of productivity growth, because those rates are so heavily affected by government regulation. We do, however, have some data related directly to the industry's productivity performance.

The U.S. Department of Commerce provides labor-productivity growth figures for the U.S. economy for the entire period since the Second World War, dividing the economy into eleven sectors which, in turn are subdivided into 66 subsectors. One of the eleven sectors is Finance, Insurance and Real Estate (FIRE), and it contains seven subsectors, including Insurance Carriers and Insurance Agents.

In terms of average productivity growth over the postwar period the FIRE sector is one of the poorest performers, with only miscellaneous services, government and construction turning in a record that was less exemplary. Output per person-hour in that group of services increased at the modest annual rate of 0.9 percent, in contrast with the average for all sectors of the economy which was some 55 percent higher than this. Not only was the average growth rate of productivity in the FIRE sector low, but it fell through most of the period, and its rate of decline relative to its initial level was greater than that of any sector other than mining and construction.

The productivity pattern of the Insurance Agents and Brokers subsector was very similar to that of the FIRE sector as a whole. Moreover, its productivity growth rate actually was negative: -0.99 percent per year over the 38 year period. In contrast, the productivity growth of the other insurance subsector, Insurance Carriers, showed no significant trend, downward or upward, and its average growth rate, 1.25 percent per year, was substantial, even if below the average for the economy, and well below the 2.77 percent growth rate for Manufacturing and the 5.37 percent for the Telephone and Telegraph subsector.

But this is only part of the story. The rising insurance rates that are so disturbing to the general public reflect not only the activities of the insurance industry proper, but also the rapidly rising costs of the services indirectly supplied by the industry - medical care, auto repair, legal services, etc. All of these, as we will see, are beset by productivity growth problems caused by technological circumstances very similar to those affecting the activities of the insurers. Together, these will be seen to contribute much of the explanation of the issues under discussion.

\section{Toward explanation: technological structure of insurance provision}

Certainly, then, the insurance industry has not accumulated an outstanding record in terms either of its productivity growth or its rate of price inflation, the two, predictably, going hand in hand. Many hypotheses have been offered to explain this phenomenon, notably (at least in the United States) the growth in lawsuits against insurance suppliers, initiated by policy holders, a development that was accompanied by a considerable increase in the magnitude of the payments awarded by juries to the complaining parties. The evidence does, in fact, offer support for this view of the matter and indicates that the role of the growth in litigation has been substantial.

However, there is reason to believe that there is considerably more to the matter, and that insurance costs would have risen considerably faster than the rate of inflation even if 
the share of policyholders who sue the insurance companies had not risen, and the awards of juries had risen only in proportion to the insurance-covered costs borne by the policyholders. To see why this is so we must look at the production process entailed in the supply of insurance services.

As in the tale of the blind men and the elephant, there are many ways in which one can legitimately describe the nature of that service and the activities entailed in its supply. One such description happens to be particularly useful for my purpose here. This views the insurance firm as a gatherer of a number of other services which it bundles into a package most useful to the party that purchases the insurance protection. The services included in the bundle encompass, of course, administration and record keeping, the provision of information, notably through the work of the insurance agents, and the collection and disbursement of money. But it also includes the provision of legal services, the (indirect) provision of services such as medical care and repair of automobiles or other damaged property.

I will argue that all of these components of the insurance bundle have a common characteristic - a tendency to rise in cost at a rate persistently and cumulatively greater than the economy's overall rate of inflation which, in turn, is engendered by the fact that each of these services in the bundle is relatively impervious to the sorts of technical change that can contribute persistently to their productivity growth.

\section{Explanation: the "cost disease", as illustrated by the case of medical care}

Medical services provide a very clear example of the sort of cost, price and productivity trends under discussion, and they also constitute a convenient illustration on which to base our analysis. It is certainly recognized widely that health care, too, suffers from a problem of cummulatively and rapidly rising prices, though the magnitudes in question are nevertheless striking.

From 1947 to 1986 the Consumer Price Index in the United States increased at an average annual of about 4.2 percent per year compounded. During the same period the annual rate of increase in the price of a visit to a general medical practitioner (the price charged by the doctor to the patient) was nearly 5.5 percent per annum (see Figure 1 which also shows, for comparison, the trends in cost of elementary education per pupil day for the same period). This difference may not seem very large, but over the 39 years in question it means that the price of a physician visit has increased by approximately 750 percent in absolute terms, or 150 percent in relation to the general price level (that is, in terms of dollars of constant purchasing power).

Over the same postwar period, the price per patient day at a hospital is reported by official statistics to have risen at an average annual rate of 11.7 percent compounded, which over the 39-year interval cumulated to more than a 9,000 percent increase. This amounts to a startling 1,750 percent rise in terms of dollars of constant purchasing power - that is, after full correction for the economy's overall inflation during this time interval.

Increases of this magnitude clearly constitute a serious threat to the quality of medical care that middle and lower income persons, whether older or younger, can afford. In an affluent society such as ours that is dedicated to promoting the general welfare - including 
the provision of medical care meeting some minimum standard of acceptability - the rising price of medical care clearly represents a problem of the utmost seriousness. ${ }^{2}$

Precisely because the problem is so serious, any attempt to deal with it rationally surely requires that we do our best to understand its causes. That these causes are far from obvious is indicated by the fact that, over much of the period in question, the real earnings of doctors in the U.S. have been virtually constant. AMA surveys (see AMA Center for Health Policy Research, Socioeconomic Characteristics of Medical Practice, 1986, p. 17 ff.) report the trends in both nominal and real net physician incomes for the decade 1975-1985. During this period, when the figures are not corrected for the effects of inflation, we find that incomes have approximately doubled, on average, rising from $\$ 56,400$ to $\$ 113,200$ an average annual rate of increase of about 7.2 percent. However, because during this period the Consumer Price Index also doubled, real average physician income at the end of the period was almost exactly where it had begun, at $\$ 56,600$ in 1975 dollars. In 1986, this figure rose slightly to $\$ 58,700$ in 1975 dollars - constituting a modest 0.5 percent increase per annum over the preceding eleven-year period.

No single all-encompassing explanation can itself account for the pattern of behavior of the price of services as complex and variegated as medical care. However, there is one component of profound importance that has been largely overlooked in discussion of rising medical costs. The rate of price increase of any product or service is heavily influenced by the rate at which the productivity of its output process has increased. Obviously, the faster labor productivity in the process of supply of the item in question has grown, the more slowly, all other things being equal, its prices will tend to rise.

These observations are of particular importance for a group of services which can be called the "personal Services". The term "personal services" refers to a category of services in which direct personal involvement of the supplier is an essential feature of the service itself or a major determinant of its quality. The point here is that, for reasons that will be noted presently, personal service industries have proved extraordinarily resistant to productivity increases. These services have consequently been characterized by persistently high rates of price increase, rates which are attributable not to inefficiency or to abnormal pursuit of financial gain or other forms of misbehavior, but to the technological character of their production. Medical care is one of these personal services industries, and the price rises which it has experienced are typical of those of personal services generally. Above all, the nature of the activity indicates why it has been resistant to labor-saving (i.e., productivity-increasing) technical change.

The quality of the product in medical care is directly dependent on the amount and quality of attention that the patient receives from the physician. Illness does not come in a few simple standardized models. As a result, assembly-line treatment is simply not an available option. A doctor who begrudges time to patients short changes them as much as a teacher who avoids spending time with students. Consequently, although spectacular progress obviously has occurred in the field of medicine and contributes - often dramatically -

2 There are offsets, however. Growing knowledge and improved medical techniques indisputably mean that patients are getting better care for their money than they were forty ycars ago. More than that. To the extent that innovation has reduced the length of treatment some illnesscs rcquire, expenditure per illness must have risen correspondingly less quickly than cost per patient day. 
to the health, longevity and comfort of patients, this advance has contributed less to reducing the amount of skilled labor on the part of the doctor ${ }^{3}$ Thus, as long as one makes no adjustment for the rising quality of the product, productivity of labor in medicine, as a general matter, shows no signs of substantial growth. ${ }^{4}$

I shall refer to productivity growth unadjusted for quality changes as "crude productivity growth". The reason I focus on crude productivity growth is that our present purpose is to account for the persistent rise in the price of a doctor's services ${ }^{5}$ - that price not being adjusted for the improvements in quality that medical research and innovation have been able to contribute. We must compare like with like - if price is unadjusted for changes in quality, the same must be done in calculating costs - if one is to be used correctly as an explanation of the other.

The low rate of growth of crude productivity in medical care relative to that in manufacturing is not a result of deliberate misbehavior or neglect. Rather, it is a consequence of the technological imperatives of supply of the medical care service in the current state of technology. The problems of medical care cannot, by and large, be standardized and rendered routine. Patients therefore cannot be cared for, or their problems even diagnosed, without individual attention. A reduction in the attention that a doctor devotes to a patient results in a concomitant reduction in the quality of medical care. The quantity of labor input, as a technological matter, is not generally reducible without degradation of that service. This is the essence of the reason that medicine has experienced very low growth in crude productivity.

This lag in crude productivity growth has a profound effect on costs and pricing because it, in effect, pits the suppliers of medical care services against the suppliers of other outputs which typically have been characterized by a substantial and persistent record of productivity growth. Over the past century productivity of the typical product in the U.S. economy, including services as well as goods, has grown at a compounded rate of some two percent per annum. By virtue of compounding, this has yielded a staggering total increase of some 1,100 percent in output per work hour, which has served as an offset to rising wage rates, fuel prices and the prices of the other inputs used in manufacturing. But competition in the markets for labor and other inputs forces input prices in medical services to go up at

${ }^{3}$ The fact that labor saving innovation is difficult to achieve in medical care does not rule out innovation of other kinds. In fact, medicine has been characterized by some of the most dramatic innovations in recent history. However, these innovations have been largely quality-enhancing, rather than costreducing. Indeed, unlike innovations in a number of other fields, it appears that changes in medicalcare technology have characteristically served to increase costs. This point has been documented to some degree and an examination of illustrative recent technological innovations strongly suggests that this point is valid as an overall characterization of the nature of the new technology that has been the instrument of progress in medicine.

${ }^{4}$ Like most generalizations, this one has exceptions. There are some areas of medical care in which technological advances seem not only to have improved the quality of service, but also to have reduced the labor component. One example sometimes cited is cataract surgery, a service pcrformed by ophthalmologists; technological advances have enabled surgeons not only to improve the quality of surgical procedures but also to reducc the amount of surgeon time, on average. per individual procedure. Such exceptions, however, do not undercut the validity of the generalization.

${ }_{5}^{5}$ It should be noted again that innovation and improvement in quality of health carc can, in principle, even reduce the average cost per illness, despite a rise in cost per hour or per day of health care, if less time is now required for recovery than was needed previously. 
more or less the same rate as the prices of inputs in the rest of the economy. As a result medical costs - with virtually no productivity growth offset to the increasing input prices will rise about two percent a year (the economy's productivity growth rate) faster than the costs of other typical products of the economy (whose input pricc incrcases are offsct by the rise in their productivity).

For example, if wages and priccs of other inputs of product $X$ rise 5 percent, but their hourly productivity rises 2 percent, then the net effect will be a 3 percent increase in the cost of a unit of product X. But a similar 5 percent rise in input costs and wages in medicine will necessarily lead to an approximate 5 percent rise in the cost of a medical care service because there is little or no intervening growth in productivity to contain the cost risc caused by the increased cost of inputs.

This "cost disease" of the personal services explains much of the persistent increase in the costs of such services as education, concerts and postal delivery, and not just those of medical care and insurance. ${ }^{6}$

\section{Cost behavior of other components of the insurance bundle}

The rapidly-rising intertemporal pattern of medical costs will come as no surprise to anyone even moderately informed on the subject, though the explanation of that persistently upward cost movement that has been offered here is not widely recognized outside the economic literature. The services encompassed in the insurance bundle, however, include a good deal more than payment of medical expenses. As already noted, also included are such heterogeneous activities as automotive repair, legal services, record keeping and the provision of information through direct client contact by insurance agents. The point that this section will make is that while the economy includes many activities that are not victims of the cost disease, the bulk of the components of the insurance bundles are infected by that malady. That is true of all or nearly all of the services in the preceding list. That is the penultimate step toward our final conclusion - that the insurance industry is the supplier of a composite of services, virtually all of which are characterized by a supply technology that makes them vulnerable to the cost disease. Once this is recognized, much of the mystery surrounding the cost trends exhibited by the industry evaporates, and it becomes clear that a major contributor to the need for cumulative real increases in insurance rates is a technological matter for which the supplier of insurance services cannot legitimately be held responsible.

A review of the insurance-component activities in turn, will indicate why each of them should be expected to be vulnerable to the cost disease. In no case will it be claimed that the activity under discussion has failed altogether to benefit from labor-saving technical progress. On the contrary, it is clear that each and every one of them has enjoyed such benefits to some degree. The point, rather, is that the resulting productivity gains can, for

\footnotetext{
${ }^{6}$ My favorite illustration of this "cost discase" phenomenon is the performance of a string quartet written by Mozart for a half-hour performance. Since the eighteenth century nothing has contributed to the productivity of a live performance of this composition. There has been no reduction either in the equipment (four instruments) or the labor time (two persons hours) required. Meanwhile, since the time of Mozart, the amount of labor and the cost of the inputs required to produce a loaf to bread has probably decreased about twenty-fold. This means that today the cost of admission to a concert, measured in terms of number of loaves of bread, must be about twenty times as high as it was at the time of Mozart.
} 
technological reasons be expected to be far more modest than those that characterize manufacturing or technologically-"progressive" services such as telecommunications.

The case of auto repair provides an obvious example. Repair personnel now have at their disposal diagnostic equipment and repair tools considerably more sophisticated than those available to them only a few decades ago. Whether or not the enhanced power of these tools has kept pace with the growing complexity of the vehicles they repair is not a question whose answer is obvious. Some growth in labor productivity has, clearly, been achieved by such technical advances. But the inherent handicap besetting such a development is brought out by a superficial comparison of automotive repair with the process of automobile manufacture. In the case of the latter everything proceeds largely according to the plans of the engineers and designers. Details of the production process for each auto component are worked out in advance and then applied repetitively and essentially without variation to many thousands of vehicles passing over each assembly line. Indeed, these attributes of the manufacturing process, standardization and predictability in detail of the process are what make it possible to use instruments such as robots, and what even permits the assembly-line operation itself. The very nature of the process facilitates and invites continual replacement of some of the human effort involved by mechanical and electronic equipment.

In contrast, automotive damage is not uniform from one car to the next. It does not come in standard packages. And in many cases the cause of the problem, as in the diagnosis of an ailing human patient, is initially unknown. The ability to discover the source of such an unstandardized problem and to deal effectively with the unique features that characterize each such repair is something which, at least up until now, is possessed only by humans who are observant, reasonably intelligent and specially trained. In other words, the participation of skilled labor in the repair process has so far proved indispensable, and the amount of time required per repair has, as a result, almost certainly fallen at a rate far slower than that experienced persistently in the production of new automobiles. With the wages of auto mechanics forced by market pressures to stay more or less abreast of those elsewhere in the economy, at least in the long run, it follows that the real costs of repair can be expected to rise higher and higher, both absolutely and relative to those of newly manufactured products.

The productivity growth record (as reported in the U.S. government's Survey of Current Business) is consistent with this analysis. While the average growth rate of the Auto Repair subsector was a respectable 1.6 percent per annum over the period 1946-86, it had a significantly declining trend throughout the period. More to the point, that average productivity growth rate was only a bit more than half of the 3.1 percent rate achieved by the manufacturing subsector Motor Vehicles and equipment.

The case of legal services is, clearly, very similar. Information services operated by computers have helped to save the lawyers $\left(8 U^{\prime}\right.$ time, as has travel by air and the availability of telephones in automobiles. But such productivity - enhancing innovations are peripheral to the work of the attorney, whose research can be assigned to paralegals but not left to machines, and whose planning of a case and its presentation in court must be done, in essence, the old fashioned way - as an almost pure expenditure of labor time. There simply is no equipment capable of reducing the labor time expended, say, per legal case to any significant degree. And, as a matter of fact, the productivity growth (or, rather, decline) 
rate for the Legal Services subsector averaged -2.26 percent compounded (!) throughout our 38 year period. The implications for the time pattern of legal costs should by this point of the discussion have become all too obvious.

The work of the insurance agents - keeping contact with prospective and actual policy holders, and the provision of information and assistance to these individuals and firms - has technological properties so similar to those of legal services that there is simply no reason to offer yet another iteration of the analysis. We have already taken note of the negative rate of productivity growth of this subsector through the postwar period.

Figure 2 provides data obtained from the U.S. Bureau of Labor Statistics on the relative trends in the prices of automobile insurance, automotive maintenance and repair, and (for comparison) the consumer price index (CPI) for the entire period 1947-1989. The CPI grew at a compound rate of a bit more than 4 percent per annum. For auto maintenance and repair the figure averaged nearly 5 percent, while that for auto insurance was about 6.5 percent. There is also a Bureau of Labor Statistics price index for legal services, but it has, unfortunately, been calculated only for the three years 1987-1989. Still, it is suggestive that during this brief period it grew some three percentage points faster per year than the CPI.

\section{Computers and administration of insurance activities}

There remains one activity of an insurance firm which is central to its operations and which has clearly undergone major modification as a result of the advent of the computer and the remarkable speed of its growth in power and the decline in its cost. Here I refer to the complex of administrative tasks of the enterprise, including record keeping, receipt and disbursement of funds, and the provision of a variety of essential types of information. Surely, these tasks have undergone a major upheaval, and it is difficult to imagine the chaos and the expense that would be entailed if the insurance companies were suddenly to be denied the use of their computers. One would then think that such administrative activities are apt to be largely immune from the cost disease. True, there are other inescapable administrative tasks, for example the making of decisions on the investment of the funds the company holds for its policyholders, whose labor productivity has probably benefited less from the availability of computer. But it is clear that a very substantial portion of the administrative activities of the firm have reaped considerable gains in productivity from this source.

Yet it transpires, on closer examination, that even these components of the insurance service are hardly immune from the cost disease. To understand why this is so it is necessary to digress very briefly into the technology of computation. For our purpose it is convenient to think of the computation process as one which employs two inputs, computer hardware, and the human labor entailed in running the machines and in providing software for their operation. The evidence indicates that the rate of growth of productivity (and, hence, the rate of fall of the costs) of computers has been spectacular - perhaps even unparalleled. By one very reasonable estimate, the hardware cost "per computation" has been declining for decades at a compounded rate of 19 percent per annum. But the rate of decline of the cost of computer operation and software creation - the human components - has been considerably more modest, if it has fallen to any significant degree. These two developments in combination have produced a result that is, apparently, not yet recognized widely: it has caused hardware to account for an ever-declining share of total computation costs in many installations. In a sense, this follows tautologically: If computer hardware and labor are used in roughly fixed proportions in the computation process, then if hardware prices decline 
far more rapidly that the real cost of the labor, the hardware cost must inevitably constitute an ever-declining proportion of the total computation budget of a computer-using enterprise. (For empirical evidence on this phenomenon see Baumol, Blackman and Wolff [1989] pp. $135-140)$.

This fall in the budgetary share of hardware, in turn, has a second consequence - the very rapidity of the decline in cost of computer hardware tends to extinguish its ability to hold back the overall costs of the final product. As hardware becomes an increasingly-insignificant component of the budget, the capacity of a further decline in hardware cost to moderate the rate of growth of that budget declines commensurately. The budget is undoubtedly dominated, more and more heavily, by the labor component of the computation process, with its resistance to increases in productivity. The consequence is that with the passage of time the cost performance of the computation process ever more closely resembles that of an activity deeply infected by the cost disease. An activity of that sort has been referred to as "asymptotically stagnant". It is characterized by an initial period of declining real cost attributable to its use of an input whose supply benefits from very rapid productivity growth. But the very rapidity of the productivity improvement in the provision of that component condemns it to an ever-more-negligible role in the total budget of the activity to which it serves as an input. That activity, increasingly deprived of its initial source of cost reduction is then left to follow the cost pattern of its remaining inputs. And if the supply of those remaining inputs is itself subject to the cost disease, inevitably the contagion spreads to the final product. From one whose overal real costs were originally falling, the activity is transformed, apparently without escape, into one whose real costs are condemned to rise persistently and cumulatively at a rate significantly greater than the economy's rate of inflation.

This theoretical analysis has direct application to the administrative activities of the insurance firm. Those activities, as has been noted, have derived great advantages from the computer revolution. However, there is every reason to conjecture that a careful study of the computation and computer hardware budgets of the insurance companies will confirm that the real rate of decline in that budget per policy holder has become negligible or has even undergone reversal. This is probably in good part attributable to the asymptonic-stagnancy characteristic of the computation process. Thus, even here, the insurance industry is not immune from the cost disease.

\section{Conclusion: the bottom line}

The public reaction to persistent and cumulatively rising insurance costs is hardly to be wondered at. Its explanation obscure, its consequences painful, it should not be surprising that this phenomenon is widely attributed to evil forces - to the demons invariably summoned to the public mind whenever it must deal with forces that seem threatening and are dimly understood. Yet we see now that there is no need to turn to villainy in incompetence as explanation. We have found here that there is a mundane set of economic relationships that are not easily escapable, to which much of the manifestation can be ascribed. The evidence, both analytical and empirical, offers support to the judgment that insurance, like most of the activities included in the bundle of products that constitute the insurance service, is yet another victim of the cost disease. Like education, artistic performance, and police protection (to give but a few additional illustrations) insurance and its component services have been condemned by technological imperative to suffer from costs that rise cumulatively 
in real magnitude with little interruption. Insurance has, consequently, not alone been a target of public suspicion played upon by political opportunists. Each economic activity affected by the cost disease has at one time or another had its problems compounded by this sort of attention.

Obviously, that makes life more difficult for the suppliers of the affected services. But it is less obvious that inisguided interference elicited by failure to understand the true sources of the problem has ultimately also been detrimental to the general welfare. Political intervention has characteristically taken the form of attempts to abolish the cost disease by fiat - in effect, to declare cost increases illegal. Price controls (often imposed via a regulatory process) on privately provided services affected by the cost disease, and underfinancing of such services that are provided by the government, have been the means generally employed to deal with them.

The folly of legislation that undertook to deal with cancer by declaring it illegal would be obvious to all, but it might well prove harmless because its consequences would be nil. The same, unfortunately, is not true of the analogous measures for treatment of the cost disease. First, the folly of the approach is hardly recognized universally - on the contrary, there is widespread belief in its virtue and efficacy. More than that, as is only too clear to those who have studied the matter systematically, price controls upon a product, typically one considered essential for the public welfare, restricts its supply, often dramatically, and tends to force the suppliers to reduce the quality of whatever decreased quantity of the output still continues to be provided to consumers. Rent controls halt housing construction and lead to accelerated deterioration of the remaining housing stock. Restrictions on medical fees create physician shortages, delays in care for patients and postponement of acquisition of improved equipment. Restrictions on insurance rates intended to contain the cost disease by a sort of excision cannot fail to have similar consequences.

In short, the explanation that has been offered here for the price trends that characterize the insurance industry does not solve the underlying problem. It leaves us with the very difficult task of educating the general public, teaching it to distinguish remedial programs that really do serve its interests from those that merely camouflage the problems and, in the process, may really exacerbate them.

None of this discussion is meant to excuse the insurance industry from working assiduously to do everything possible to avoid waste and cut down costs. Every way of doing so helps the public as well as the firms. Some significant cost savings may well be available and, if so, urgently need to be pursued. Still, if the cost disease analysis is right, such economizing measures will delay the progress of the disease, but not keep it in remission foreover.

\section{REFERENCES}

American Medical Association, Center for Health Policy Research, Socioeconomic Characteristics of Medical Practice, Chicago: 1986.

BAUMOL, W. J., BLACKMAN, S. A. B. and WOLFF. E. N. [1989] Productivity and American Leadership: the Long View, MIT Press, Cambridge (Mass.).

U.S. Department of Commerce, Survey of Current Business, Washington, D.C.: U.S. Government Printing Office, various years.

U.S. Department of Labor. Bureau of Labor Statistics, Consumer Price Index Reports, Washington, D.C. 


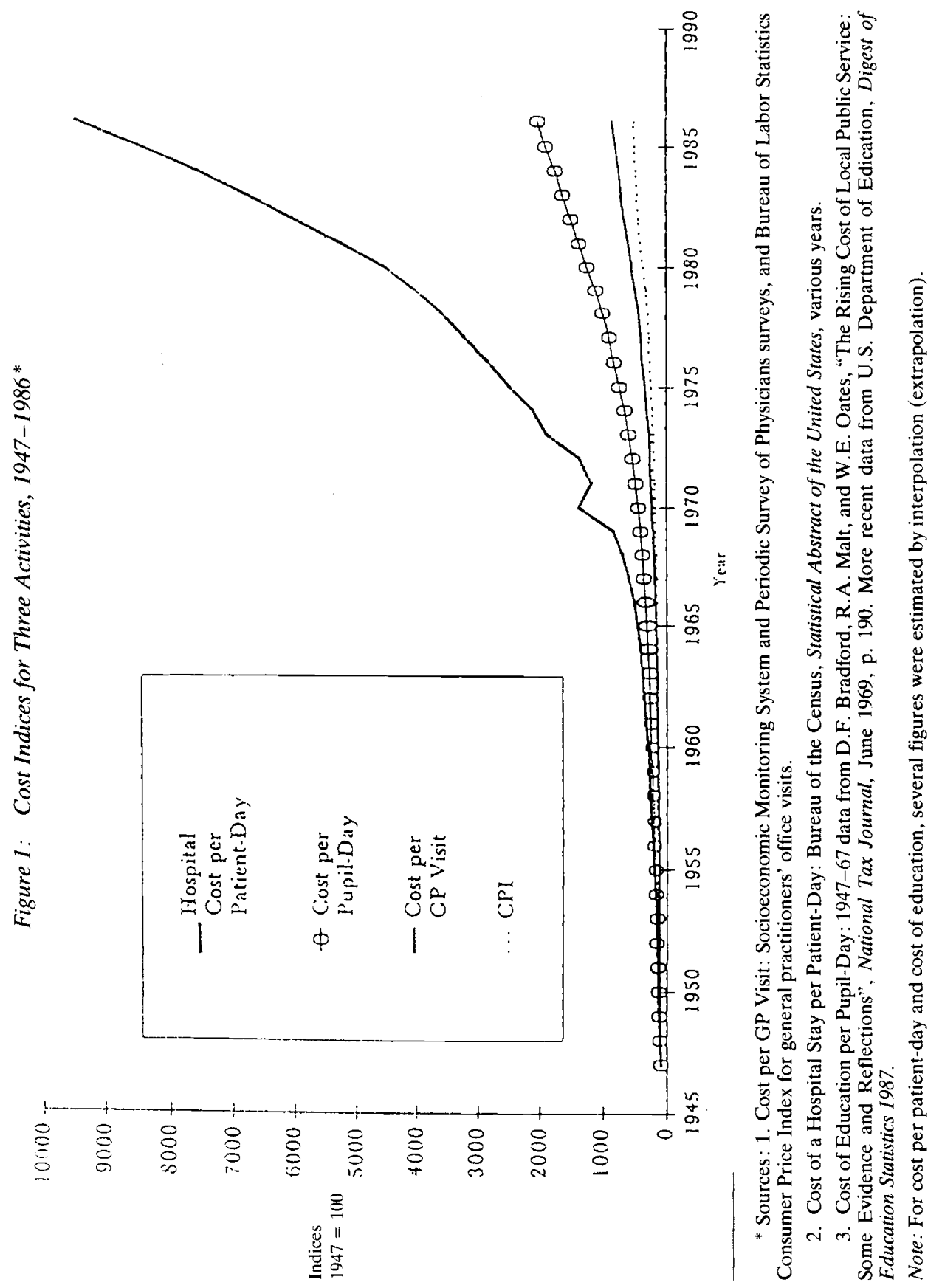




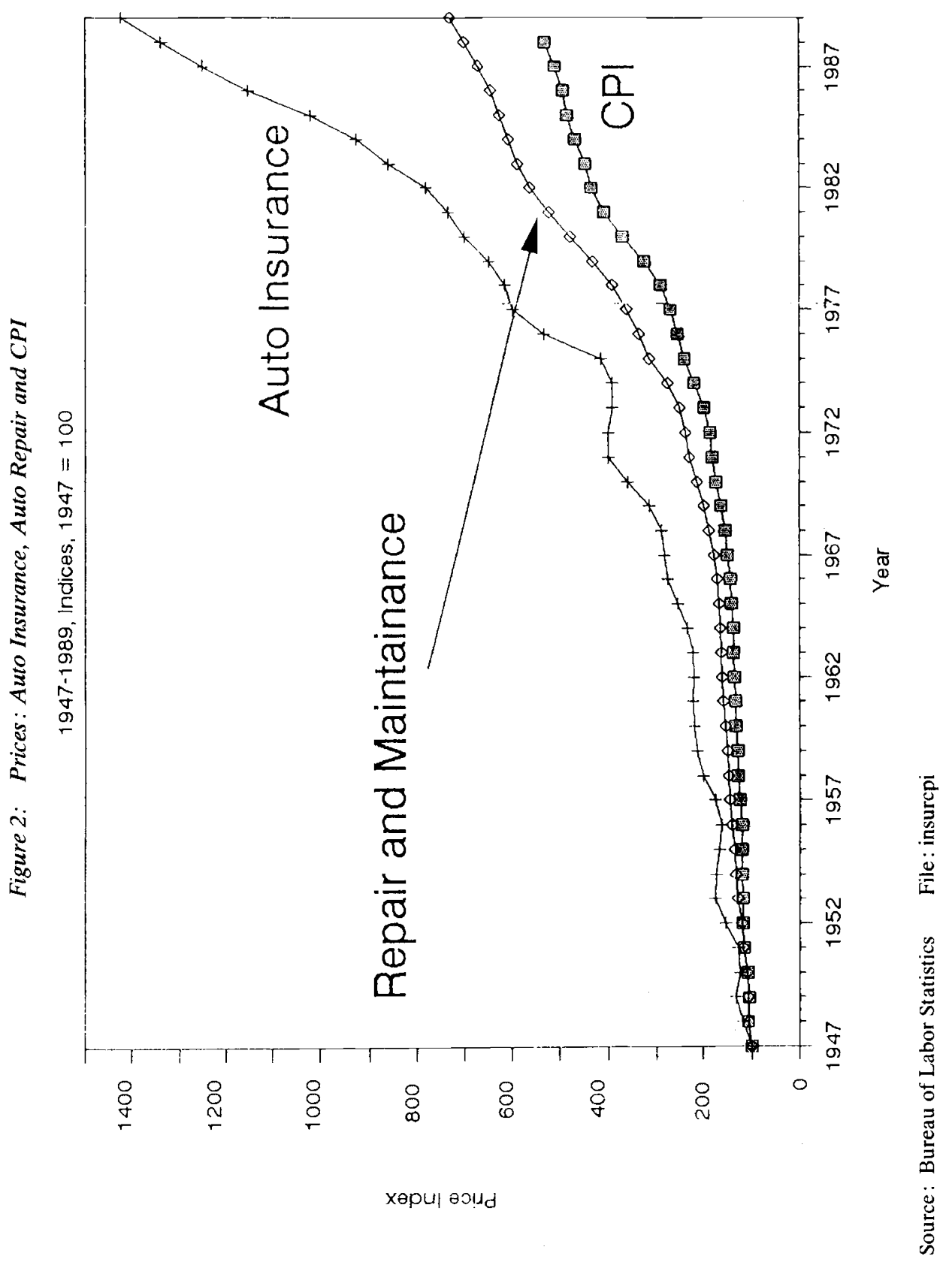

